MONOTERPENES

PINENES

EMISSION

SAMPLING
SPRUCE

p-CYMENE

AIR POLLUTION

ANALYSIS

Open access manuscript version of Holzforschung 46 (1992) 99-102

Link to publisher

\title{
Terpenes emitted to air from TMP and sulphite pulp mills
}

Ann-Margret Strömvall and Göran Petersson

Comparable studies of terpene emissions were made for:

Barking of logs and pulpwood

$\underline{\text { Kraft pulp mills }}$ 
Terpenes Emitted to Air from TMP and Sulphite Pulp Mills

By Ann-Margret Strömvall and Göran Petersson

Department of Chemical Environmental Science, Chalmers University of Technology.

S-412 96 Göteborg, Sweden 


\section{Summary}

Terpenes were studied at two Swedish pulp mills processing wood from Norway spruce (Picea abies). Field samples were adsorbed from air on Tenax cartridges and analyzed in the laboratory by thermal desorption and gas chromatography.

The emissions from a large thermomechanical pulp (TMP) plant consisted mainly of chemically unchanged hydrocarbon monoterpenes from the wood. The major monoterpenes were $\alpha$-pinene (>50\%) and $\beta$-pinene ( $25 \%)$. The proportions of ten additional components were determined in the process emissions, which may be recovered as turpentine. The process emissions from a sulphite pulp mill consisted predominantly of the alkylbenzene $p$-cymene, formed from monoterpenes by acid reactions in the digesters. The contribution of the emissions to photooxidant formation in the surrounding region may be significant for both types of mills.

Keywords

Spruce wood

Pulp mills

Terpenes

Cymene

Turpentine

Air pollution

Photooxidants

Gas chromatography

Picea abies 


\section{Introduction}

Volatile olefinic and aromatic hydrocarbons are presently the objects of great environmental concern with regard to photooxidant formation. In complex atmospheric reactions (Atkinson, 1990), a variety of phytotoxic compounds are formed which may contribute to forest decline. Within these groups of hydrocarbons, terpenes and cymene emitted from the pulp industry are particularly reactive.

An early contribution to research on these new aspects on pulp mill emissions dealt with monoterpenes from groundwood pulp production (Strömvall and Petersson, 1990). The present study is devoted to monoterpenes and cymene emitted from TMP and sulphite pulp mills. 


\section{Experimental}

\section{TMP mill}

Bravikens Pappersbruk is a rather new (1977) newsprint mill based on an annual production of 400000 tons of thermomechanical pulp.The mill is owned by Holmen Paper AB and located on the Swedish east cost very near to the town Norrköping inside the fjord Bråviken. The pulpwood is taken from stems of Norway spruce from the region. The logs are barked and chipped at the mill, but $\sim 10 \%$ of the chips are delivered from local saw-mills. Continuous TMP production is effected by 21 refiners (mainly Sunds Defibrator). The chips are pretreated with steam from the refining process. Reported annual mill emissions are 160 tons of $\mathrm{NO}_{\mathrm{x}}$ and 130 tons of $\mathrm{SO}_{2}$.

\section{Sulphite mill}

Billeruds Bruk is an old sulphite pulp mill which now delivers well over 30000 tons yearly for the integrated production of mainly greaseproof paper. The mill is located in the small town of Säffle just west of lake Vänern and uses Norway spruce from the region. The wood is chipped at the mill and seasoned rapidly in a silo at an elevated temperature (Dillner et al., 1981). The pulp is produced with magnesium bisulphite at $\sim 130^{\circ} \mathrm{C}$ in four batch digesters. The digester relief gases are combined with gases from the burning of spent liquor. The gases are emitted to air after passing a neutralizing water scrubber for removal of sulphur dioxide and recovery of the cooking chemicals. Reported annual mill emissions are 70 tons of $\mathrm{NO}_{x}$ and 250 tons of $\mathrm{SO}_{2}$.

\section{Sampling and analysis}

Terpenes were sampled on Tenax adsorbent cartridges connected to portable air sampling pumps. The air volumes varied in the $\mathrm{ml}$ to the litre range, and the total monoterpene concentrations from below $0.1 \mathrm{mg} / \mathrm{m}^{3}$ in external mill plumes up to $100 \mathrm{mg} / \mathrm{m}^{3}$ near certain process emissions. Before sampling of the acid process emissions of the sulphite mill, the front end of the Tenax column was treated with bicarbonate, to prevent acid reactions of terpenes in the cartridge.

In the laboratory, the terpenes were determined by thermal desorption $\left(200^{\circ} \mathrm{C}\right)$ combined with temperature-programmed $\left(2^{\circ} \mathrm{C} \mathrm{min}^{-1}\right.$ from $\left.0^{\circ} \mathrm{C}\right)$ gas chromatography. The column ( $25 \mathrm{~m} \times 0.33 \mathrm{~mm}$ i.d.) was a fused silica capillary 
with a cross-linked methylsilicone (BP-1, $0.5 \mu \mathrm{m})$ as the stationary phase. Detector (FID) response was set equal for all terpenes. Further analytical data were given in previous studies of monoterpenes (Strömvall and Petersson, 1990 and 1991). 


\section{Results and discussion}

\section{Process emissions and turpentine recovery}

The composition of monoterpenes in the major process emissions is reported in Table 1 for the TMP and the sulphite pulp mills. These emissions are of particular interest with respect to potential turpentine recovery.

The results from the TMP mill represent emissions with steam from the refiners, passed through the chip pretreatment vessel. The major species were $\alpha$-pinene and $\beta$-pinene. Limonene, 3-carene, $\beta$-phellandrene and camphene constituted 1-10\% each of total hydrocarbon monoterpenes. Six additional species, including $p$-cymene, were present in proportions between 0.1 and $1 \%$. A large number of sesquiterpenes added up to $5 \%$ of the total amount of monoterpenes. The chromatogram given in Figure 1 visualizes the composition and the chromatographic separation of the monoterpenes. The sesquiterpenes elute later.

Combined turpentine and heat recovery can be efficiently achieved at TMP mills (Rockhill and Hostetter, 1982). In Sweden, partial turpentine recovery (0.3 kg per ton of pulp) was recently inroduced at a large northern mill (Ortviken, Sundsvall). Selected TMP process emissions add up to $0.9 \mathrm{~kg}$ per ton of pulp according to measurements reported by the industry. The potential for turpentine recovery at the presently studied mill amounts to several hundred tons per year since the monoterpene content in Norway spruce exceeds $1 \mathrm{~kg}$ per ton of dry wood. Compared to the common sulphate turpentine from kraft mills, turpentine from mechanical pulping offers a superior quality because it is free from malodorous sulphur contaminants. The monoterpene composition given in Table 1 is similar to that observed for steam distilled wood of Norway spruce (Kimland and Norin, 1972) and should reflect that of the turpentine to be recovered.

The composition of the emissions from the sulphite process is entirely different, with $p$-cymene as the predominant species. This is explained by the conversion of monoterpenes to cymene under the acid sulphite digesting conditions. Only the saturated monoterpene tricyclene appears to be unaffected. The reported sample was taken during the final phase of digestion from relief gases after their passage of the alkaline water scrubber. Samples taken directly on the aggressive gases from the digester at the very end of the pulping process demonstrated a similar predominance of cymene with still lower proportions of monoterpenes.Satisfactory reproducibility for duplicate samples indicated that unwanted acid chemical conversions of the monoterpenes in the sampling cartridge were prevented by the treatment of the adsorbent front with bicarbonate. 
Table 1. Composition (\%) of monoterpenes and p-cymene emitted to air from the TMP and sulphite pulp processing of Norway spruce wood.

Thermomechanical pulp milla (refiner emissions)

\begin{tabular}{lcll}
\hline$\alpha$-pinene & 58 & myrcene & 1.0 \\
$\beta$-pinene & 26 & $p$-cymene & 0.8 \\
limonene & 5.1 & tricyclene & 0.4 \\
3-carene & 3.5 & terpinolene & 0.3 \\
$\beta$-phellandrene & 3.0 & -terpinene & 0.1 \\
camphene & 1.7 & $\alpha$-thujene & 0.1 \\
\hline
\end{tabular}

Sulphite pulp mill ${ }^{b}$ (digester emissions after scrubber)

\begin{tabular}{lcll}
\hline$p$-cymene & 94 & tricyclene & 0.4 \\
$\alpha$-pinene & 2.2 & $\beta$-pinene & 0.4 \\
camphene & 1.9 & limonene & 0.3 \\
3-carene & 0.6 & $\beta$-phellandrene & 0.1 \\
\hline
\end{tabular}

a) Bravikens Pappersbruk, Norrköping 3/14/91.

b) Billeruds Bruk, Säffle 3/21/91. 


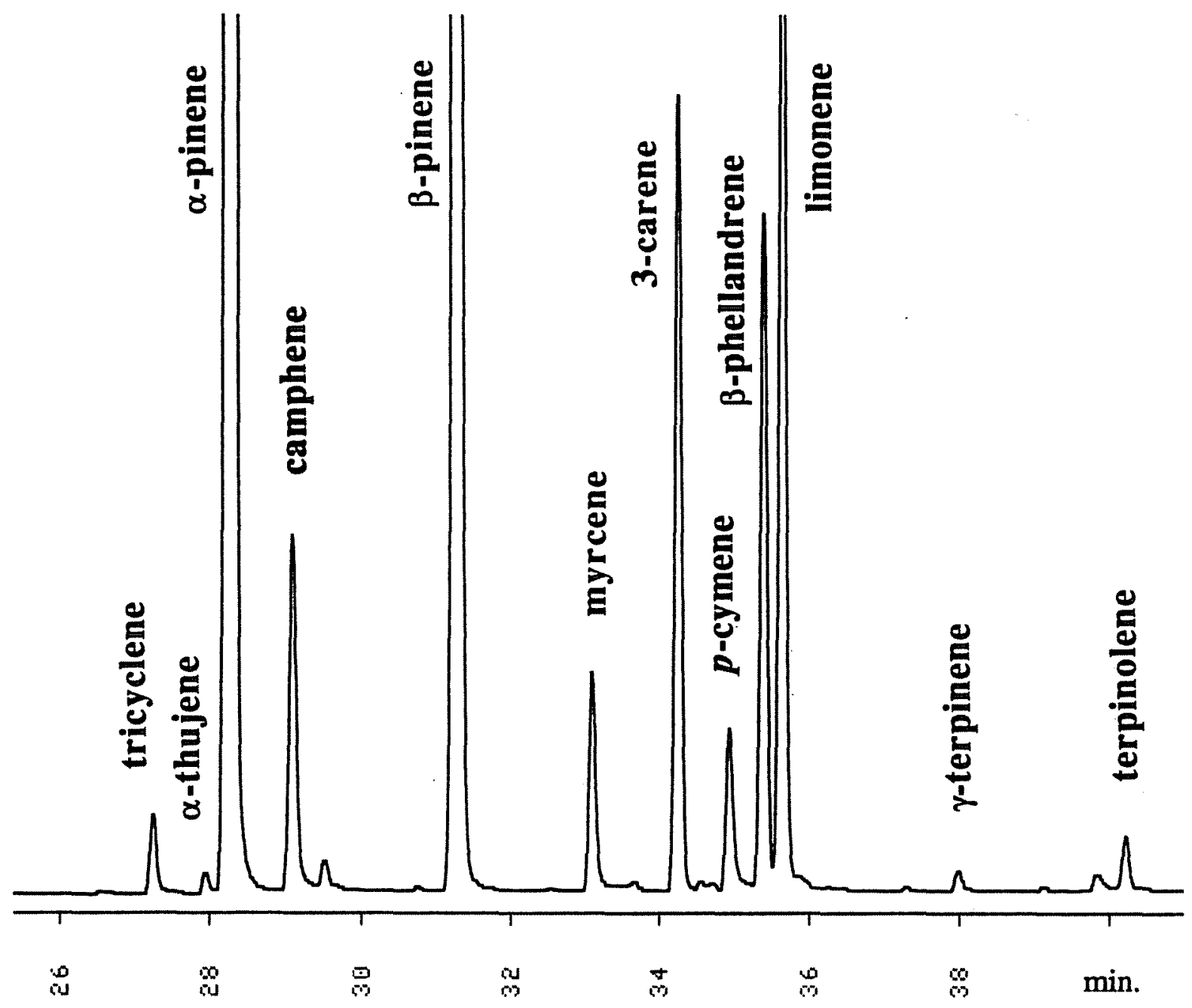

Fig. 1. Gas chromatographic separation of monoterpenes in the major emissions to air from of a thermomechanical pulp mill processing Norway spruce (Bravikens Pappersbruk, Norrköping, $3 / 14 / 91$, sample taken near roof vent of refiner steam after its use for preheating of feeded wood chips). 
Cymene was recovered from a Swedish sulphite pulp mill (Skoghall, north of lake Vänern) already during World War II (Waller, 1941). The yield was $0.4 \mathrm{~kg}$ per ton of pulp and the purity $90 \%$ with terpenes as the remainder. This indicates a recovery potential of 10-20 tons per year for the studied mill, which produces less than $10 \%$ of the Swedish acid sulphite pulp from Norway spruce. Presently, no Swedish mill recovers cymene.

\section{Mill plumes and subplumes}

All samples taken at the TMP mill demonstrated monoterpene compositions similar to that given in Table 1 for the major process emissions. This includes samples from wood chipping and chip piles, from the paper machines and from the downwind mill plume at ground level (Table 2).The monoterpene composition range conforms well with that observed for a stone groundwood mill (Strömvall and Petersson, 1990). It should be observed that terpenes reaching the paper machines with process water and pulp evaporate from the paper line at the elevated temperatures used for drying. The composition of monoterpenes remaining in the paper should be similar to that of the monoterpenes emitted to air.

At the sulphite mill studied, prominent pre-process emissions arise from the particular ageing of spruce chips in circulating moist air of $60^{\circ} \mathrm{C}$. The monoterpene composition (Table 2) was similar to that observed for the emissions from the preceeding chipping of fresh spruce wood. The proportion of sesquiterpenes was $1 \%$ of total monoterpenes in the chipping emissions but $5 \%$ in the seasoning silo emissions, i. e. as great as in the process emissions from the TMP mill. Longifolene was found to constitute more than $30 \%$ of the total amount of sesquiterpenes in all these emissions. Samples taken downvind from the mill contained spruce wood monoterpenes with variable proportions of $p$-cymene from the process emissions. The proportion of $p$-cymene was normally below $20 \%$ at ground level because the major process emissions are emitted through a $60 \mathrm{~m}$ high stack and only during the short digester relief periods. Near the paper machines, $p$-cymene was the most prominent species, as expected. A residual content of $p$-cymene in the greaseproof paper produced might be of concern with respect to its use for fat-containing food.

\section{Environmental aspects}

Structurally, the monoterpenes are alkenes whereas $p$-cymene is an alkylbenzene. Alkenes and alkylbenzenes are now given the highest priority in efforts to decrease 
Table 2. Composititon (\%) of monoterpenes in non-pulping emissions and in outside-mill plumes.

\begin{tabular}{lcccc}
\hline & \multicolumn{2}{c}{ TMP mill } & \multicolumn{2}{c}{ Sulphite mill } \\
& Paper mill $^{\mathrm{a}}$ & Plume $^{\mathrm{b}}$ & Chip ageing $^{\mathrm{c}}$ & Plume $^{\mathrm{d}}$ \\
& & & & \\
\hline$\alpha$-pinene & 55 & 57 & 58 & 44 \\
$\beta$-pinene & 26 & 26 & 23 & 19 \\
limonene & 6.1 & 3.9 & 6.7 & 4.3 \\
3-carene & 3.7 & 5.4 & 3.4 & 4.2 \\
$\beta$-phellandrene & 3.2 & 2.7 & 2.7 & 3.1 \\
camphene & 2.3 & 3.0 & 2.6 & 2.5 \\
$p$-cymene & 1.7 & 0.7 & 1.0 & 21 \\
& & & & \\
\hline
\end{tabular}

a) Near roof vent from dry section of paper machine, 3/14/91.

b) Sample taken $800 \mathrm{~m}$ downwind from refiner area, 8/21/90, 11-13 $\left(20^{\circ} \mathrm{C}\right)$.

c) Venting from seasoning chip silo, 3/18/91.

d) Sample taken $200 \mathrm{~m}$ downwind from digester area, $11 / 2 / 90,15-16.30\left(0^{\circ} \mathrm{C}\right)$. 
hydrocarbon emissions in Europe as a means of attacking the photooxidant problem. Both alkenes and alkylbenzenes give rise to a variety of phytotoxic photooxidants in complex atmospheric chemical reactions (Atkinson, 1990). In Table 3, physical data for $p$-cymene and monoterpenes are compared with those of ethene and toluene. The short lifetimes of cymene and monoterpenes result in prominent first-day formation of photooxidants and elevated photooxidant levels within short distances of the mills.

Among prominent anthropogenic emissions of alkylbenzenes (mainly toluene and xylene), those of $p$-cymene from sulphite mills belong to the most reactive. Concurrent emissons of $\mathrm{Cl}_{2}$ from bleaching further increases the photochemical reactivity of the mill plume (Hov, 1985). The combined effects of the large emissions of sulphur dioxide from sulphite mills are also detrimental, particularly with regard to forest decline (Stangl et al., 1988). Decreased emissions can be attained by cymene recovery and by incineration of collected gas streams.

The monoterpenes react much faster in air than the prominent conventional alkenes (mainly ethene and propene) which are often controlled by environmental authorities. Biogenic occurence of ethene as well as monoterpenes is essential to the ecosystem, while environmental hazards arise from anthropogenic emissions and from interactions with other air pollutants (Strömvall and Petersson, 1990). Several TMP mills are presently among the largest industrial point sources of monoterpenes. Environmentally justified demands, including turpentine recovery, are to be expected.

The location of the TMP mill studied at the innermost part of a long and narrow fjord is particularly unfavourable with regard to photooxidants. Circulation of air pollutants with land and sea breeze has been reported to raise photochemical levels strikingly for a similar industrial location (Hov, 1985). The emissions from the TMP mill are also added to the large urban emissions from the town of Norrköping. Forest decline has been reported in the region. 
Table 3. Physical data and approximate lifetimes ${ }^{a}$ in air of selected alkenes and alkylbenzenes.

$\alpha$-pinene
ethene
limonene
toluene

a) Daylight, reaction mainly with the $\mathrm{OH}$ radical (Atkinson, 1990). 


\section{References}

Atkinson, R. 1990. Gas-phase tropospheric chemistry of organic compounds: A review. Atmos. Environ. 24A, 1-41.

Dillner, B., R. Gustavsson, J. Ryhman and B. Swan. 1981. Accelerated chip seasoning at the Billerud mill. Pulp Pap. Can. 82, 391-396.

Hov, O. 1985. The effect of chlorine on the formation of photochemical oxidants in southern Telemark, Norway. Atmos. Environ. 19, 471-485.

Kimland, B. and T. Norin. 1972. Wood extractives of common spruce, Picea abies (L.) Karst. Sven. Papperstidn. 75, 403-409.

Rockhill, R.G. and D.W. Hostetter. 1982. Evaporator/reboiler recovers steam, turpentine from TMP refiners. Pulp. Pap. 58, 106-108.

Stangl, H., D. Kotzias and F. Geiss. 1988. How forest trees actively promote acid deposition. Naturwissenschaften 75, 42-43.

Srömvall, A.-M. and G. Petersson. 1990. Ambient monoterpenes from stone groundwood pulp production. Holzforschung 44, 449-452.

Strömvall, A.-M. and G. Petersson. 1991. Conifer monoterpenes emitted to air by logging operations. Scand. J. For. Res. 6, 253-258.

Waller, A. 1941. Om cymol och en enkel metod för dess utvinning i nästan rent tillstånd. Sven. Papperstidn. 44, 427-429.

\section{Acknowledgements}

The authors are grateful to Dr Hans Arne at Billeruds Bruk and Tekn lic Per Ängstrand at Bravikens Pappersbruk for constructive cooperation. 